\title{
ACCURACY OF GUIDED IMPLANT INSERTION IN MANDIBULAR FREE-END SADDLE AREAS USING STEREOLITHOGRAPHIC SURGICAL STENT
}

\author{
Waleed M. Abd Alkader ${ }^{* *}$ BDS, Magued H. Fahmy² PhD, Adham A. ElAshwah² \\ $P h D$
}

\begin{abstract}
INTRODUCTION: The success of implant therapy depends primarily on appropriate treatment planning and properly performed implant placement surgery.Guided implant surgery (template based guided cavity preparation and guided implant insertion) is effective to guide the implant placement.This can be achieved by means of a surgical guide Stent.Stents are designed in conventional methods or stereolithography which allows the fabrication of surgical guides from 3D computer generated models for precise placement of the implants.

OBJECTIVES: Assess the accuracy of stereolithographic surgical stent to orientate implant insertion in mandibular free-end saddle areas. MATERIALS AND METHODS: A total of 12 implants will be placed in patients having mandibular free end- saddle areas selected from the outpatient section of the department of Oral and Maxillofacial Surgery, Faculty of Dentistry, Alexandria University, after virtual implant planning with implant studio software, the implants will be inserted using stereolithographical design of surgical stent then measuring the deviation between the planned implant position before the surgery and the actual position of placed implant after surgical procedure.

RESULTS: Evaluation of the accuracy of placement was done by measuring the overall deviations between virtually planned and surgically placed dental implants. The mean of total angular difference in implant with stereolithographic stent were $10.9 \pm 9.4^{\circ}$. While The Mean of total coronal differences in stereolithographic guided implant were $0.96 \mathrm{~mm} \pm 0.7 \mathrm{~mm}$. The Mean of total apical differences in stereolithographic guided implant were $1.8 \pm 1.3 \mathrm{~mm}$
\end{abstract}

CONCLUSIONS: The stereolithographic surgical template was sufficiently accurate in transferring the planned implant position to the surgical field relative to the implant angulation and point of entrance.

KEYWORDS: Implant studio, stereolithography, guided implant surgery, surgical Stents.

1- Instructor in Oral and Maxillofacial surgery Department, Alexandria Police Hospital.

2- Professor in Oral and Maxillofacial surgery Department, Faculty of Dentistry, Alexandria University.

*Corresponding author:

E-mail: smiletome604@yahoo.com

\section{INTRODUCTION}

The success of implant therapy depends primarily on appropriate treatment planning and properly performed implant placement surgery (1) and angulation of mandibular free-end saddles may affect pressure from the prosthesis on the abutments, so as to cause high stress concentrated in some areas, this may easily lead to implant failure (2).

Accurate implant placement may reduce the surgical complications such as nerve damage, hemorrhage and unintentional perforation of the sinuses, floor of nose, and cortical plates, in addition to the success rate of osseointegration (3).

Even since the first dental implant has been introduced by Branemark et al in 1969, more than four decades ago, dental practiitionars and researchers have been searching for various methods for improving the accuracy of the surgical placement of implants. Advances in dental imaging technology utilizing computed tomography (CT) has been proven especially useful when determining the installation sites of dental implants (4).

Once the treatment plan has been defined, radiographic imaging has the potential to facilitate precise surgical planning including the choice of implant shape (cylinder or tapered) diameter and in cases where bone atrophy is present, the length and type of horizontal or vertical bone augmentation (5).

Diagnostic casts, panoramic radiographs do not provide three-dimensional information required for correct positioning and orientation of the implant. Optimal restoration is facilitated by ideal implant placement.Three factors considered when inserting implants, position, depth and angulations.It has been well documented in literature that the implants placed using stents are more accurately positioned than those without the stent (6).

The introduction of cone-beam computed tomography (CBCT) for the maxillofacial region provides opportunities for dental practitioners to request multi-plane imaging. CBCT allows the creation in "real time" of images not only in the axial plane but also in the coronal, sagittal and even oblique or curved image planes $(7,8)$.

Proper planning of dental implant position and its exact transfer to the operation site in the oral cavity can be considered as one of the most important factors for longterm success of implant supported prosthetic restoration (9). CAD/CAM technique and the development of 3D implant planning software have led to an evolution of novel treatment concepts in dental implant treatment.CT and 3D implant software provide surgeons with 3D information of the patient's bony structures. Furthermore, the combination of such image technologies and the CAD/CAM technology allows fabrication of surgical templates and implant supported prosthesis preoperatively based on the virtual treatment planning $(10,11)$.

Stereolithography, a rapid prototyping technology, a newer outcome in dentistry allows the fabrication of surgical guides from 3D computer generated models for precise placement of the implants. The surgical templates fabricated by this technology are preprogrammed with 
individual depth, angulation, mesio-distal and labio-lingual positioning of the implant. Nowadays computer-guided surgery for implant placement using stereolithographic templates is gaining popularity among surgeons and patients $(12,13)$.

The aim of the study is to evaluate the accuracy of implant placement using stereolithographic surgical stents in mandibular free saddle-end areas.

\section{MATERIALS AND METHODS}

The study was performed in the Faculty of Dentistry, Alexandria University after gaining the approval of the Research Ethics Committee. A total of 6 mandibular free saddle areas in healthy patients selected from outpatient section of Department of Oral and Maxillofacial Surgery of Alexandria University, two implants were inserted in each free saddle area. An approved consent was obtained from each patient in this study.

\section{Criteria for patient selection}

Inclusion criteria

1-Mandibular free saddle area(s)

2-Age from 25-40 years.

3-Good oral hygiene.

4-Sufficient bone volume

5-Adequate vertical distance between the alveolar crest and the inferior alveolar canal to accommodate implants

\section{Exclusion criteria}

1-Inadequate inter-occlusal space.

2-Heavy smoker.

3-Para-functional habits.

4-Systemic diseases such as uncontrolled diabetes and osteoporosis ...etc.

5-Immune-compromised individuals.

6-History of chemotherapy or radiotherapy.

7-Patients on anticoagulant, corticosteroids.

\section{MATERIALLS}

Implant system

- Conventional, two pieces, screw type, titanium dentium (Dentium superLine dental implant) implant system.

- Color Coding by Diameter) yellow, green, blue) which corresponding diameter $(3.6,4,4.5) \mathrm{mm}$ with different lengths $(8,10,12)$.

- The implant has double threaded tapered design with flat end and conical hex connection between implant and abutments.SuperLine prosthetics consist of Dual Milling Abutment, Angled Abutment, Direct-Casting Abutment, Angled Abutment and Metal-Casting Abutment

\section{METHODS}

\section{I.Pre-surgical phase}

\section{a. Clinical examination}

- Patient's data were taken; name; gender and age.

- Medical and dental history were taken.

- Clinical examination was performed both extra orally and intra orally for assessment of decayed and filled teeth, oral hygiene assessment, inter-occlusal distance and interproximal distance with period of edentulousness

\section{b. Radiographic examination}

- Orthopantomogram (OPG) to primary assessment the distance between the inferior alveolar nerve and the implant side.

- Cone Beam Computer Tomography (CBCT) for assessment of bone length and thickness, implant position, angulation, depth, and the planned position of ridge of bone length and thickness, and for virtual treatment plan

- CBCT images were acquired with J.Morita (Morita 3DX; J Morita mfgcorp., Kyoto, Japan ) cone beam 3D imaging system

\section{c. Construction of the surgical guide stent}

- The treatment plane was done using implant studio software (figure 1)

- Patients who were qualified using the inclusion and exclusion criteria had diagnostic impression for the mandibular arch made with irreversible hydrocolloid and diagnostic cast was fabricated

- The DICOM format obtained from CBCT was sent to 3 shape implant studio software together with the diagnostic cast where optical scan was done to the cast. The processing of the stereolithography interface (STL)-format data acquired from the optical scan overlapping the data obtained from the CBCT device in a DICOM format, which allowing simulatinous viewing of the axial, 3D, panoramic and crosssectional images of the computer monitor.Transferral of the virtual project to a1:1 scale model with a rapid prototyping technique and subsequent realization of a surgical stent obtained according to the CBCT scans and diagnostic cast by using the principle of stereolithography.Once the stereolithographic guides were retained from 3D printer (Planmeca.com), they were checked on the models.This for checking the stability and insure the appliance fit well before the surgeries were scheduled. After confirming the fit of the stereolithographic guides, patients were scheduled for surgery

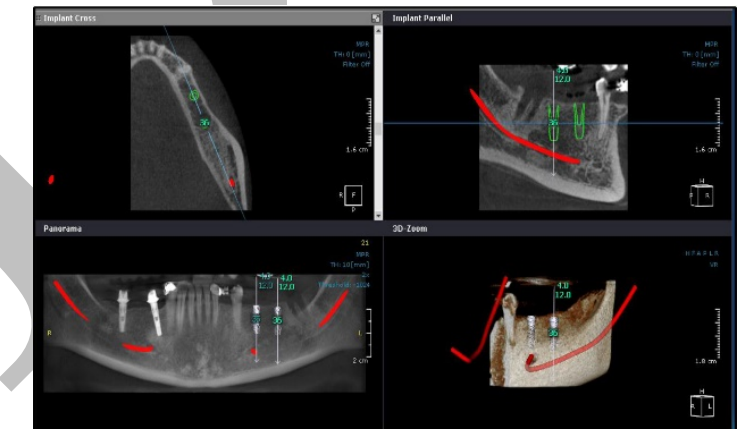

Figure (1): Virtual treatment plan.

\section{II.Surgical phase}

- All patients had been operated under Inferior alveolar nerve block (IANB) technique of dental anesthesia (Articaine Hydrochloride 4\% and adrenaline 1:100,000.) (Septanest; Septodont, France).

- The sterolithographic surgical templates were inserted into the jaw and the precise fit was visually and manually controlled before surgery. (figure 2)

- Drilling was performed using RealGuide (3diemme.it) surgical kit which has sequential drills with increasing diameters. (figure 3)

- The Implants were inserted and guided by the fixture mount that fitted in the sleeve. (figure 4)

- After implant insertion, the templates were removed and healing abutments were put. 


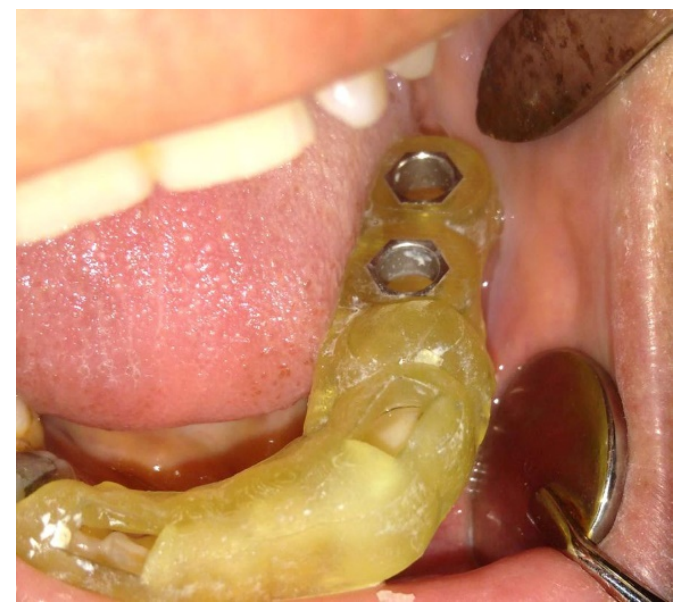

Figure (2): Stent in patient mouth.

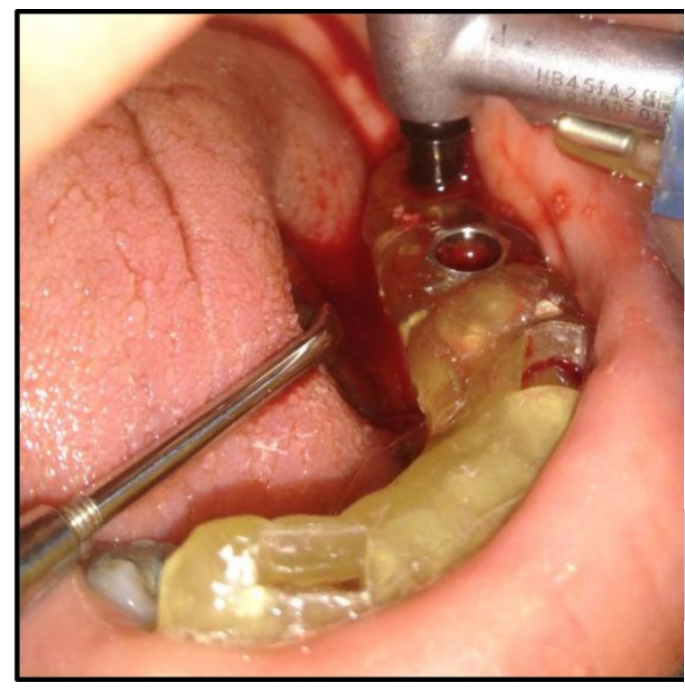

Figure (3): Drilling procedure of implant.

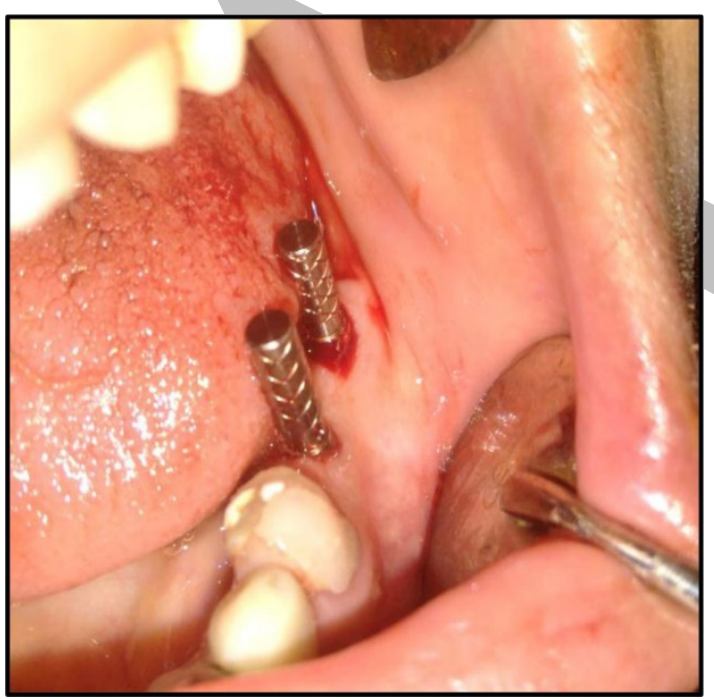

Figure (4): Implant inserted.

\section{III.Post-surgical phase}

- Postoperative CBCTs were taken for the patients, cold fomentation for the first 24 hours, warm mouth wash on the next day, oral hygiene instructions.

- Postoperative medications including anti-biotic and nonsteroidal anti-inflammatory analgesics drugs.

- Antibiotic: amoxicillin/clavulanic acid (Augmentin; manufactured by Glaxosmithkline) 1g:1 capsule every 12 hours for 6 days post operatively.
- NSAID: ibuprofen 400mg (manufactured by Abbott multinational pharmaceutical company) 1 tablet every 8 hours daily after meals for 4 days.

\section{IV.Follow up}

a) Clinical evaluation

- The patients were evaluated clinically at regular follow up intervals after the 1st, the 2nd weeks and 3th months post operatively to evaluate any complication such as infection, pain and swelling.

\section{b) Radiographic evaluation}

- The preoperative and postoperative scans were then over $\neg$ lapped using a dedicated algorithm, which allowed the com $\neg$ parison of the virtually planned and the actual implant posi $\neg$ tions. Three deviation parameters between each planned and placed implant were measured.All measure $\neg$ ments were performed using implant studio software.(figure 5)

- For analyzing the accuracy, the planned position of the implant was compared with the actual position of the implant after insertion. Several measuring points were used for the comparison of these positions which are coronal difference, apical difference and angular difference.

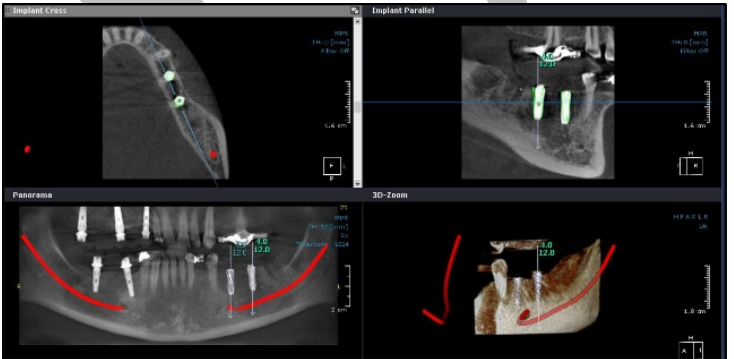

Figure (5): postoperative CBCT (Accuracy measurement)

\section{V.Prosthetic phase}

Final restorations (porcelain fused to metal crown) were placed 3 months after surgery

\section{VI.Statistical analysis}

Data was collected, calculated, tabulated and analyzed by 3shape implant studio software.

\section{RESULTS}

- A total of 12 implants were placed with flapless surgery using CAD CAM surgical stent. Six patients (3 females and 3 males) who were suffering from missing mandibular posterior teeth, were included in the study. All patients had undergone surgical procedures for implant placement and delayed loading.

- All patients were followed up and the results were registered as regards both clinical and radiographic evaluation.

- Evaluation of the accuracy of placement was done by measuring the overall deviations between virtually planned and surgically placed dental implants.

- Analysis was based on a comparison of preoperative and postoperative CBCT images for all 12 implants.

- Angular deviation, coronal deviation and apical deviation, were determined. Data collected were tabulated. (Figure 6) (Table 1) 


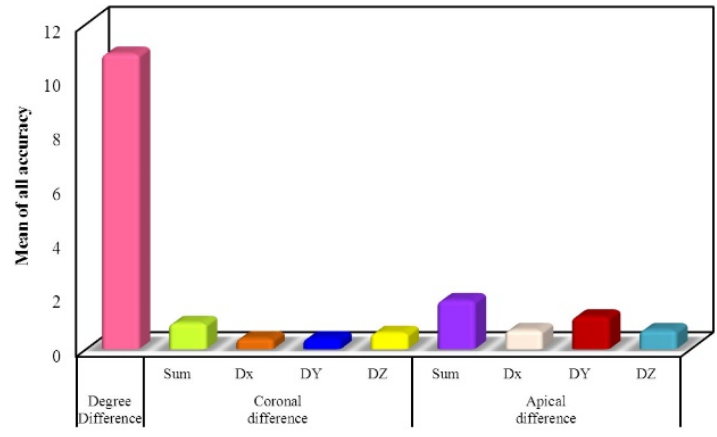

Figure (6): Distribution of the studied cases according to accuracy of implants placed with CADCAM stents ( $n=15)$.

Table (1): Distribution of the studied cases according to accuracy of implants placed with CAD-CAM stents ( $\mathrm{n}=15)$.

\begin{tabular}{|c|c|c|c||}
\hline All accuracy & $\begin{array}{c}\text { Min. }- \\
\text { Max. }\end{array}$ & $\begin{array}{c}\text { Mean } \pm \\
\text { SD. }\end{array}$ & Median \\
\hline $\begin{array}{c}\text { Degree } \\
\text { Difference }\end{array}$ & $2.2-29.1$ & $10.9 \pm 9.4$ & 7.1 \\
\hline $\begin{array}{c}\text { Coronal } \\
\text { difference }\end{array}$ & & & \\
\hline Sum & $0.3-2.8$ & $0.96 \pm 0.7$ & 0.7 \\
\hline Dx & $0.0-1.3$ & $0.4 \pm 0.4$ & 0.3 \\
\hline DY & $0.02-0.8$ & $0.4 \pm 0.3$ & 0.3 \\
\hline DZ & $0.01-2.8$ & $0.6 \pm 0.8$ & 0.2 \\
\hline Apical difference & & & \\
\hline Sum & $0.5-4.1$ & $1.8 \pm 1.3$ & 1.3 \\
\hline Dx & $0.0-2.2$ & $0.7 \pm 0.7$ & 0.4 \\
\hline DY & $0.1-3.3$ & $1.2 \pm 1.0$ & 0.9 \\
\hline DZ & $0.04-2.9$ & $0.7 \pm 0.9$ & 0.2 \\
\hline & & & \\
\hline
\end{tabular}

\section{1-Evaluation of the angular deviation}

Mean angular differences in implants were $10.9 \pm 9.4^{\circ}$ with a minimum recorded value of $2.2^{\circ}$ and a maximum recorded value of $29.1^{\circ}$.

\section{2-Evaluation of the coronal deviation}

Coronal and apical differences were measured and analyzed for total distances and also for the 3 axes ( $\mathrm{x}, \mathrm{y}, \mathrm{z}$ positions) where:

- Dx is the differences at the bucco-lingual position

- Dy is the differences at the mesio-distal position and

- $\mathrm{Dz}$ is the differences at the apico-coronal position

- Total coronal differences in implants were $(0.96 \pm 0.7 \mathrm{~mm})$ with a minimum recorded value of $0.30 \mathrm{~mm}$ and a maximum recorded value of $2.8 \mathrm{~mm}$.

- Mean coronal differences at the bucco-lingual position (Dx) in implants were $0.4 \pm 0.4 \mathrm{~mm}$ with a minimum recorded value of $0.0 \mathrm{~mm}$ and a maximum recorded value of $1.3 \mathrm{~mm}$.

- Mean coronal differences at the mesiodistal position (Dy) in implants were $0.4 \pm 0.3 \mathrm{~mm}$ with a minimum recorded value of $0.02 \mathrm{~mm}$ and a maximum recorded value of 0.8 $\mathrm{mm}$.

- Mean coronal differences at the apicocoronal position (Dz) in implants were $0.6 \pm 0.8 \mathrm{~mm}$ with a minimum recorded value of $0.01 \mathrm{~mm}$ and a maximum recorded value of 2.8 $\mathrm{mm}$.

\section{3-Evaluation of the apical deviation}

- Total apical differences were $(1.8 \pm 1.3 \mathrm{~mm})$ with a minimum recorded value of $0.5 \mathrm{~mm}$ and a maximum recorded value of $4.1 \mathrm{~mm}$.

- Mean apical differences at the bucco-lingual position (Dx) in implants were $0.7 \pm 0.7 \mathrm{~mm}$ with a minimum recorded value of $0.0 \mathrm{~mm}$ and a maximum recorded value of $2.2 \mathrm{~mm}$.

- Mean apical differences at the mesio-distal position (Dy) in implants were $1.2 \pm 1.0 \mathrm{~mm}$ with a minimum recorded value of $0.1 \mathrm{~mm}$ and a maximum recorded value of $3.3 \mathrm{~mm}$.

- Mean apical differences at the apico-coronal position (Dz) in implants were $0.7 \pm 0.9 \mathrm{~mm}$ with a minimum recorded value of $0.04 \mathrm{~mm}$ and a maximum recorded value of 2.9 $\mathrm{mm}$.

4-Assessment of implant distance to the inferior alveolar nerve (Table 2)

- The mean of the distances between the planned implants preoperatively to the inferior alveolar nerve was $4.30 \pm 2.69$ mm with minimum value of $2.17 \mathrm{~mm}$ and maximum value of $6.60 \mathrm{~mm}$.

- The mean of the distances between the placed implants to the inferior alveolar nerve were $3.88 \pm 2.23 \mathrm{~mm}$ with minimum value of $0.30 \mathrm{~mm}$ and maximum value of $6.36 \mathrm{~mm}$.

Table (2): Statistical analysis of the studied cases according assessment of implant distance to the inferior alveolar nerve

\begin{tabular}{||c|c|c|c|c||}
\hline & Planned implants & Placed implants & $\mathbf{Z}$ & $\mathbf{p}$ \\
\hline Min. - Max & $2.17-6.60$ & $1.40-6.36$ & & \\
Mean \pm SD. & $4.30 \pm 2.69$ & $3.88 \pm 2.23$ & $1.988^{*}$ & $0.047^{*}$ \\
Median & 3.45 & 3.05 & & \\
\hline
\end{tabular}

Z: Z for Wilcoxon signed ranks test

$\mathrm{P}^{*}$ : Statistically significant at $\mathrm{p} \leq 0.05$

\section{DISCUSSION}

Dental implants have been an increasing used procedure in treatment of partially or fully edentulous patients for the last three decades. When there is no distal abutment, implantretained fixed crown (s) or bridge (s) will be the treatment options) (14).

CAD/CAM technology uses data from cone beam computerized tomography scan (CBCT) (15) to plan implant rehabilitation, then transfers this pre-surgical plan to the surgical site using stereolithographic drill guides) (16).

Accuracy of CAD/CAM technology in dental implant planning and predictable transfer of the pre-surgical plan to the surgical site has been documented $(17,18)$. However, the effectiveness has not yet become an established fact and still needs ongoing research

The aim of the study is to evaluate the accuracy of implant placement using stereolithographic surgical stents in mandibular free saddle-end areas 12 implants were placed using the stereolithographic surgical stents.

In this study 12 implants were placed in 6 patients at the posterior mandible with free end saddle areas using the stereolithographic surgical stents. Six patients were selected from the Outpatient Clinic of the Oral Maxillofacial Surgery Department, Faculty of Dentistry, Alexandria University. Their ages ranged between 28 and 50 years with mean age of 42 years.

Patients were selected free from systemic diseases because that may complicate the surgical procedure or the 
healing process of the implant procedure as advocated by Bolender (19) in 1988, Dhanrajani and Al-Rafee (20) in 2005 and Moy et al (21) in 2005. Also, as Balshi and Wolifinger (22) reported in 1997, patients were selected free from para-functional habits such as bruxism and clenching, because the magnitude of the forces are high, the duration of the forces are extensive and the direction of the forces are more horizontal than axial to the implant.

Heavy smokers were also excluded from this study.This followed the studies of Holahan et al (23) in 2008 and Clementini et al (24) in 2014, where they concluded that exposure to smoking has a harmful effect on the peri-implant bone loss that eventually lead to implant failure.

In this study CBCT was performed for all patients preoperatively. Corresponding to the studies conducted by Cassetta et al (25) in 2013 and Bornstein et al (26) in 2014, they reported that the use of CBCT in implant dentistry vary from preoperative analysis regarding specific anatomic considerations, site development using grafts and treatment planning to postoperative evaluation. Along with, lower radiation dose, reduced costs and the relative grey density values of CBCT images making it a useful substitute for computerized tomography (CT) $(27,28)$.

Evaluation of the accuracy of placement was done by measuring the overall deviations between virtually planned and surgically placed dental implants. The mean of total angular difference in implant with stereolithographic stent were $10.9 \pm 9.4^{\circ}$. These differences were close to angular differences reported by Di Giacomo et al (29) in 2005 (7.25 $\left.\pm 2.67^{\circ}\right)$ and Valente et al (30) in $2009\left(7.9^{\circ}\right)$.

The Mean of total coronal differences in stereolithographic guided implant were $0.96 \mathrm{~mm} \pm 0.7 \mathrm{~mm}$. These differences were close to coronal differences reported by Di Giacomo et al (28) (1.45 $\pm 1.42 \mathrm{~mm})$ and Farley et al (30) in 2013 (1.43 $\pm 0.67 \mathrm{~mm})$.

The Mean of total apical differences in stereolithographic guided implant were $1.8 \pm 1.3 \mathrm{~mm}$. These differences were close to apical differences reported by Valente et al (31) (1.6 mm), Farley et al (30) (1.72 \pm 0.61 $\mathrm{mm})$, Schneider et al (32) in 2009 (1.96 mm) and D’haese (33) in 2012 (1.64 mm).

The deviations in this technique may be attributed to the acquisition of tomographic image, inaccurate planning, inaccurate positioning of the guide resulting in displacement during implant placement, improper guide fixation.Mechanical errors caused by angulation of the expanders during expansion, reduced mouth opening, bone density, the length of the implants and human errors, such as not following the implant installation protocol, all influence the accuracy (34-36).

An error might also occur during the manufacturing of the surgical template for example in the simulation software, the precision of the stereolithographic machine, production and quality control, rigidity and physical properties of the material used, the precision of the guide cylinders and metal tubes, and verification of the guide (37).

\section{CONCLUSION}

The accuracy of the stereolithograpthic surgical guides used for the current study was well accepted within the range of results. The guided surgery is a new modality for safe and easy implant insertion so a stereolithographic stent for implant placement is considered a good tool with excellent outcomes.

\section{CONFLICT OF INTEREST}

The authors declare that they have no conflicts of interest.

\section{REFERENCES}

1-Shotwell JL, Billy EJ, Wang HL, Oh TJ. Implant surgical guide fabrication for partially edentulous patients. J Prosthet Dent 2005;93:294-7.

2-Akca K, Iplikcio H. Evaluation of the effect of the residual bone angulation on implant-supported fixed prosthesis in mandibular posterior edentulism. Part II: 3-D finite element stress analysis. Implant Dent 2001;10:238-45.

3-Goodacre CJ, Bernal G, Rungcharassaeng K, Kan JY. Clinical complications with implants and implant prostheses. J Prosthet Dent 2003;90:121-324.

4-Breanemark PI, Adell R, Breine U, Hansson BO, Lindstrom J, Ohlsson A. Intra-osseous anchorage of dental prostheses. I. Experimental studies. Scand J Plast Reconstr Surg 1969;3:81-100.

5-Wismeijer D, Casentini P, Chiapasco M. Pre-operative assessment and prosthetic planning: The edentulous patient. In: Wismekjer D, Buser D, Belser U (eds). ITI treatment guide. Berlin, Germany: Quintessence Publishing; 2010. p.13-34.

6-Engelman MJ, Sorensen JA, Moy P. Optimum placement of osseointegrated implants. J Prosthet Dent. 1988;59:467473.

7-American Dental Association and U.S. Department of Health and Human Services. The selection of patients for dental radiographic examinations. Chicago: American Dental Association; 2004.

8-William C, Allan G. Clinical applications of cone-beam computed tomography in dental practice. J Can Dent Assoc 2006;72:75-80.

9-Mischkowski RA, Zinser MJ, Neugebauer J, Kübler AC, Zöller JE. Comparison of static and dynamic computerassisted guidance methods in implantology. Int J Comput Dent 2006;9:23-3575.

10-Yong LT, Moy PK.Complications of computer-aideddesign/computer-aided-machining-guided (NobelGuide) surgical implant placement: an evaluation of early clinical results. Clin Implant Dent Relat Res 2008;10:123-7.

11-Balshi SF, Wolfinger GJ, Balshi TJ. Surgical planning and prosthesis construction using computed tomography, CAD/CAM technology, and the Internet for immediate loading of dental implants. J Esthet Restor Dent 2006;18:312-23.

12-Lal K, White GS, Morea DN, Wright RF. Use of stereolithographic templates for surgical and prosthodontic implant planning and placement. Part II. A clinical report. J Prosthodont 2006;15:117-22.

13-Amorfini L, Storelli S, Romeo E.Rehabilitation of a dentate mandible requiring a full arch rehabilitation. Immediate loading of a fixed complete denture on 8 implants placed with a bone-supported surgical computer-planned guide: a case report. J Oral Implantol 2011;37:106-13.

14-Parein AM, Eckert SE, Wollan P, Keller EE. Implant reconstruction in the posterior mandible: a long-term retrospective study. J Prosthet Dent 1997;78:34-42.

15-Marchack CB. CAD/CAM-guided implant surgery and fabrication of an immediately loaded prosthesis for a 
partially edentulous patient. The Journal of prosthetic dentistry. 2007;97:389-94.

16-Naziri E, Schramm A, Wilde F. Accuracy of computerassisted implant placement with insertion templates. GMS Interdisciplinary Plastic and Reconstructive Surgery DGPW. 2016;5:Doc15.

17-Ersoy AE, Turkyilmaz I, Ozan O, McGlumphy EA. Reliability of implant placement with stereolithographic surgical guides generated from computed tomography: clinical data from 94 implants. J Periodontol. 2008;79:1339-45.

18-Nikzad S, Azari A. A novel stereolithographic surgical guide template for planning treatment involving a mandibular dental implant. J Oral Maxillofac Surg. 2008;66:1446-54.

19-Bolender CL. Indications and contraindications for different types of implant therapy. J Dent Educ 1988;52:757-9.

20-Dhanrajani PJ, Al-Rafee MA. Single-tooth implant restorations: a retrospective study. Implant Dent. 2005;14:125-30.

21-Moy PK, Medina D, Shetty V, Aghaloo TL. Dental implant failure rates and associated risk factors. Int $\mathrm{J}$ Oral Maxillofac Implants. 2005;20:569-77.

22-Balshi TJ, Wolfinger GJ. Two-implant-supported single molar replacement: interdental space requirements and comparison to alternative options. Int $\mathrm{J}$ Periodontics Restorative Dent. 1997;17:426-35.

23-Holahan CM, Koka S, Kennel KA, Weaver AL, Assad DA, Regennitter FJ, et al. Effect of osteoporotic status on the survival of titanium dental implants. Int J Oral Maxillofac Implants. 2008;23:905-10.

24-Clementini M, Rossetti PH, Penarrocha D, Micarelli C, Bonachela WC, Canullo L. Systemic risk factors for periimplant bone loss: a systematic review and meta-analysis. Int J Oral Maxillofac Surg. 2014;43:323-34.

25-Cassetta M, Sofan AA, Altieri F, Barbato E. Evaluation of alveolar cortical bone thickness and density for orthodontic mini-implant placement. J Clin Exp Dent. 2013;5:e245-52.

26-Bornstein MM, Scarfe WC, Vaughn VM, Jacobs R. Cone beam computed tomography in implant dentistry: a systematic review focusing on guidelines, indications, and radiation dose risks. Int $\mathrm{J}$ Oral Maxillofac Implants. 2014;29:55-77.

27-Chasioti E, Sayed M, Drew H. Novel techniques with the aid of a staged CBCT guided surgical protocol. Case Rep Dent. 2015; 8:39-76.
28-Mello LA, Garcia RR, Leles JL, Leles CR, Silva MA. Impact of cone-beam computed tomography on implant planning and on prediction of implant size. Braz Oral Res. 2014;28:46-53.

29-Di Giacomo GA, Cury PR, de Araujo NS, Sendyk WR, Sendyk CL. Clinical application of stereolithographic surgical guides for implant placement: preliminary results. J Periodontol. 2005;76:503-7.

30-Valente F, Schiroli G, Sbrenna A. Accuracy of computeraided oral implant surgery: a clinical and radiographic study. Int J Oral Maxillofac Implants. 2009;24:234-42.

31-Farley NE, Kennedy K, McGlumphy EA, Clelland NL. Split-mouth comparison of the accuracy of computergenerated and conventional surgical guides. Int $\mathrm{J}$ Oral Maxillofac Implants. 2013;28:563-72.

32-Schneider D, Marquardt P, Zwahlen M, Jung RE. A systematic review on the accuracy and the clinical outcome of computer-guided template-based implant dentistry. Clin Oral Implants Res. 2009;20:73-86.

33-D'Haese J, Van De Velde T, Komiyama A, Hultin M, De Bruyn H. Accuracy and complications using computerdesigned stereolithographic surgical guides for oral rehabilitation by means of dental implants: a review of the literature. Clin Implant Dent Relat Res 2012; 14: 321-35e.

34-Dreiseidler T, Neugebauer J, Ritter L, Lingohr T, Rothamel D, Mischkowski RA, et al. Accuracy of a newly developed integrated system for dental implant planning. Clin Oral Implants Res. 2009;20:1191-9.

35-Viegas VN, Dutra V, Pagnoncelli RM, de Oliveira MG. Transference of virtual planning and planning over biomedical prototypes for dental implant placement using guided surgery. Clin Oral Implants Res. 2010;21:290-5.

36-Bruno V, Badino M, Riccitiello F, Spagnuolo G, Amato M. Computer Guided Implantology Accuracy and Complications. Case Rep Dent. 2013;54:70-42.

37-Pozzi A, Tallarico M, Marchetti M, Scarfo B, Esposito M. Computer-guided versus free-hand placement of immediately loaded dental 97 implants: 1 - year post-loading results of a multicentre randomised controlled trial. Eur J Oral Implantol. 2014;7:229-42. 